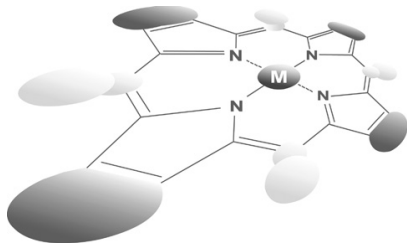

\title{
Synthesis of alkylthio substituted pyridoporphyrazines and their photophysicochemical properties
}

\author{
Keiichi Sakamoto*a,b ${ }^{\star}$, Shouta Watabiki ${ }^{\mathrm{b}}$, Satoru Yoshino ${ }^{\mathrm{a}}$ and Tomoe Komoriya ${ }^{\mathrm{a}}$ \\ ${ }^{a}$ Department of Sustainable Engineering, College of Industrial Technology, Nihon University, \\ 1-2-1 Izumi-cho, Narashino-shi, Chiba-ken 275-8575, Japan \\ ${ }^{\mathrm{b}}$ Academic Major of Applied Molecular Chemistry, Graduate School of Industrial Technology, Nihon University, \\ 1-2-1 Izumi-cho, Narashino-shi, Chiba-ken 275-8575, Japan
}

Received 12 September 2017

Accepted 19 October 2017

\begin{abstract}
Phthalocyanine and their related compounds are utilized as various applications, such as photosensitizing agents for photodynamic therapy of cancer. In this study, zinc bis(thiodidecylbenzo)bis(pyrido)porphyrazines, especially zinc bis(1,4-didecylthiobenzo)-bis(3,4-pyrido)porphyrazine and zinc bis(1,4-didecylthiobenzo)-bis(2,3-pyrido)porphyrazine were synthesized. Quaternation of the pyridine nitrogen in these provides an amphiphilic property. Photoexcited triplet lifetime of synthesized and quaternized zinc bis(1,4-didecylthiobenzo)-bis(3,4-pyrido)porphyrazine and zinc bis(1,4-didecylthiobenzo)-bis(2,3-pyrido)porphyrazine were reported using laser-flash photolysis and singlet oxygen quantum yields by the 1,3-diphenylisobenzofurne method.
\end{abstract}

KEYWORDS: pyridoporphyrazine, quaternation, laser-flash photolysis, triplet lifetime, PTDF method.

\section{INTRODUCTION}

Phthalocyanines and their related compounds possess similar molecular structures as porphyrins. They are known to be used as important colorants since their discovery, and have attracted attention as functional materials for various applications such as catalysts, laser light absorbers in data storage systems, electron-charge carriers in photocopiers, photoconductors in chemical sensors, photo-antenna devices in photosynthesis, photovoltaic cells and photosensitizers [1-3]. For these the applications, the absorption maximum of phthalocyanines and their related compounds must be moved to the near-infrared region [1-3]. When this occurs, the photosensitization properties

\footnotetext{
${ }^{\vartheta}$ SPP full member in good standing

*Correspondence to: Keiichi Sakamoto, email: sakamoto.keiichi@ nihon-u.ac.jp. tel: +81 47-474-2554, fax: +81 47-474-9759.

This is an open access article published by World Scientific Publishing and distributed under the terms of the Creative Commons Attribution (CC BY) 4.0 License, which permits use, distribution and reproduction in any medium, provided the original author(s) and source are credited.
}

of phthalocyanines and their related compounds can be utilized for both phototherapy and photovoltaic cells.

Phthalocyanines and their related compounds are particularly known to have potential as photosensitizers of photodynamic therapy of cancer (PDT) [2, 4-8]. Phthalocyanines and their related compounds used for PDT are required to have long life-time triplet states and show strong absorption of far red light between 600 and $800 \mathrm{~nm}$, values of wavelengths which have a greater penetration of tissue and satisfactory photosensitization of singlet oxygen [2]. In general, it is known that phthalocyanines and their related compounds having no-substituents are insoluble in common organic solvents. Insolubility of unsubstituted phthalocyanines and their related compounds present greater problems for use as photosensitizers in PDT. The shortcoming of phthalocyanines and their related compounds can be overcome by introduction of substituents such as alkyl or aryl groups onto the ring system of the phthalocyanine. Alkyl or aryl substituted phthalocyanines and their related compounds become a lipophilic property $[9,10]$.

At present, photosensitizers for PDT in medical institutions have been using hematoporphyrins, which possess a few weak points such as shorter absorption maxima around $500 \mathrm{~nm}$, lower metabolization rates and 
a side effect of dermatitis solaris. In contrast, phthalocyanines and their related compounds exhibit suitable properties for PDT photosensitizers and they show no cytotoxity when no light is irradiated [2].

The strongest absorption maxima of phthalocyanines and their related compounds in visible region called the $\mathrm{Q}$ band can be moved by bathochromic effect to introduce an electron-donating substituent at a non-peripheral $(1,4$, $8,11,15,18,22,25)$ position. For PDT photosensitizers, the absorption maxima of phthalocyanines and their related compounds are best when moved to the nearinfrared region $[2,9]$.

As phthalocyanine-related compounds, zinc bis(didecylthiobenzo)-bis(pyrido)porphyrazines have been synthesized by cross cyclotetramerization from 3,6didecylthiophthalonitrile and 3,4-dicyanopyridine or 2,3-dicyanopyridine for 1:1 mol ratio. The phthalocyanine related compounds containing a pyridine ring in place of one or more of benzenoid rings are interesting compounds because quaternation of pyridine nitrogen is expected to confer solubility in an aqueous media $[2,11]$. Furthermore, the authors have reported that the length of triplet lifetime alkylbenzopyridoporphyrazines increased with the number of pyridine rings in the molecule [2]. Moreover, Shinokubo and co-workers reported that the ultraviolet-visible (UV-Vis) spectra of $N$-heterocyclic compounds shifted to longer wavelengths [12].

Zinc bis(1,4-didecylbenzo)-bis(2,3-pyrido)porphyrazines exhibited solubility in organic solvents $[9,13]$ and was expected to show a tumor affinity. Then, quaternation of the pyridine nitrogen in zinc bis(thiodidecylbenzo)bis(pyrido)porphyrazines were conferred solubility in an aqueous media. Thus, the quaternation of metal bis(1,4didecylbenzo)-bis(2,3-pyrido)porphyrazines provided an amphiphilic property $[9,13]$.

Non-peripheral thio-substituted metal phthalocyanines were synthesized [1-3, 13, 14]. They displayed Q band peaks between 780 and $860 \mathrm{~nm}$. The $\mathrm{Q}$ band of thio-substituted zinc phthalocyanines appeared at around $800 \mathrm{~nm}[1-3,13,14]$.

Currently, asymmetric phthalocyanines are synthesized in order to achieve a shift of the absorption maxima towards the near-infrared region [15-17].

We report herein synthesis of zinc bis(1,4-didecylthiobenzo)-bis(3,4-pyrido)porphyrazine (5) and zinc bis(1,4-didecylthiolbenzo)-bis(2,3-pyrido)porphyrazine (6). We also report their photophysicochemical properties obtained from photoexcited triplet lifetimes using laserflash photolysis and singlet oxygen quantum yields by the 1,3-diphenylisobezofurane (DPBF) method.

\section{EXPERIMENTAL}

\section{Equipment}

Infrared (IR) spectra were recorded on a Shimadzu IR-8400A spectrometer using potassium bromide
$(\mathrm{KBr})$ pellets and a Perkin-Elmer Spectrum 65 FT-IR spectrometer by an attenuated total reflection (ATR) method. UV-vis spectra were measured on a Shimazdu UV-2400PC spectrometer. Each sample was prepared at $1.0 \times 10^{-5} \mathrm{M}$ in chloroform $\left(\mathrm{CHCl}_{3}\right)$ or $\mathrm{N}, \mathrm{N}$-dimethylformamide (DMF). Fluorescent spectra were recorded at $1.0 \times 10^{-5} \mathrm{M}_{\text {in }} \mathrm{CHCl}_{3}$ on a Nihon Bunko Jasco FP-6600 spectrofluorometer. The proton magnetic resonance $\left({ }^{1} \mathrm{H}\right.$ NMR) spectra were measured on a Bruker Advance 400s and a Bruker Advance III 500 in dimethyl sulfoxide (DMSO)- $d_{6}$ or $\mathrm{CHCl}_{3}-d$ using tetramethylsilane (TMS) as the internal standard. Elemental analysis was carried out using a Perkin-Elmer $2400 \mathrm{CHN}$ instrument. Mass (MS) spectra were taken with a Nihon Denshi Joel JMS-AX500 mass spectrometer. Melting points were measured with a Stanford research system MPA 100 optimelt automated system. The molecular orbital calculation was achieved in order to obtain the allowed highest occupied molecular orbital (HOMO) - lowest unoccupied molecular orbital (LUMO) energy level with MOPAC 2016. Photoexcited triplet lifetime was observed using Laser-flash photolysis (Tokyo Instruments) at $1.5 \times$

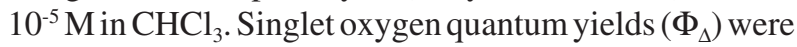
estimated by DPBF method using zinc phthalocyanine as standard material for $\Phi_{\Delta}^{\text {Std }}=0.67$ [5]. Compounds 5 and 6 containing DPBF as a singlet oxygen quencher in $1.7 \mathrm{~mL}$ of $3 \times 10^{-5} \mathrm{M}$ DMF solution was irradiated at $635 \mathrm{~nm}$ Laser $(2 \mathrm{~mW})$ for $10 \mathrm{~s}, 6$ times.

\section{Materials}

All chemicals were purchased from Aldrich, Tokyo Chemical Industry or Wako Chemicals. They were used as received without further purification. For chromatographic separation, silica gel was used (60, particle size 0.063-0.200 nm, 7734-grade; Merck). Thin-layer chromatography (TLC) was performed using Merck 60 $\mathrm{F}_{254}$ silica gel.

\section{Synthesis of phthalocyanine-related compounds and their intermediates}

The synthetic route to zinc bis(1,4-thiodidecylbenzo)bis(3,4-pyrido)porphyrazine (5) and zinc bis(1,4-thiodidecylbenzo)-bis(2,3-pyrido)porphyrazine (6) is shown in Scheme 1. Target compounds $\mathbf{5}$ and $\mathbf{6}$ were synthesized by cross cyclotetramerization between 3,6-bis(decylthio) phthalonitrile (2), which was prepared using phthalonitrile3,6-ditrifluoromethanesulfate (1), and 3,4-dicyanopyridine (3) or 2,3-dicyanopyridine (4).

Preparation of phthalonitrile-3,6-ditrifluoromethanesulfate (1). Compound 1 was synthesized in accordance with our previous report [3]. The crude product was recrystallized from dichloromethane to afford 1 (6.35 g, 50\%) as colorless needles. Found: $\mathrm{C}, 28.32 \%$; H, $0.48 \% ; \mathrm{N}, 6.59 \%$. Calcd. for $\mathrm{C}_{10} \mathrm{H}_{2} \mathrm{~F}_{6} \mathrm{~N}_{2} \mathrm{~S}_{2} \mathrm{O}_{6}: \mathrm{C}, 28.31 \%$; $\mathrm{H}, 0.48 \%$; F, 26.87\%; N, 6.60\%; O, 22.63\%; S, $15.12 \%$. IR (ATR): $\mathrm{cm}^{-1} 3115\left(v_{\mathrm{C}-\mathrm{H}}\right), 2550\left(v_{\mathrm{C}-\mathrm{N}}\right), 1601\left(v_{\mathrm{C}-\mathrm{C}}\right), 1472$ 


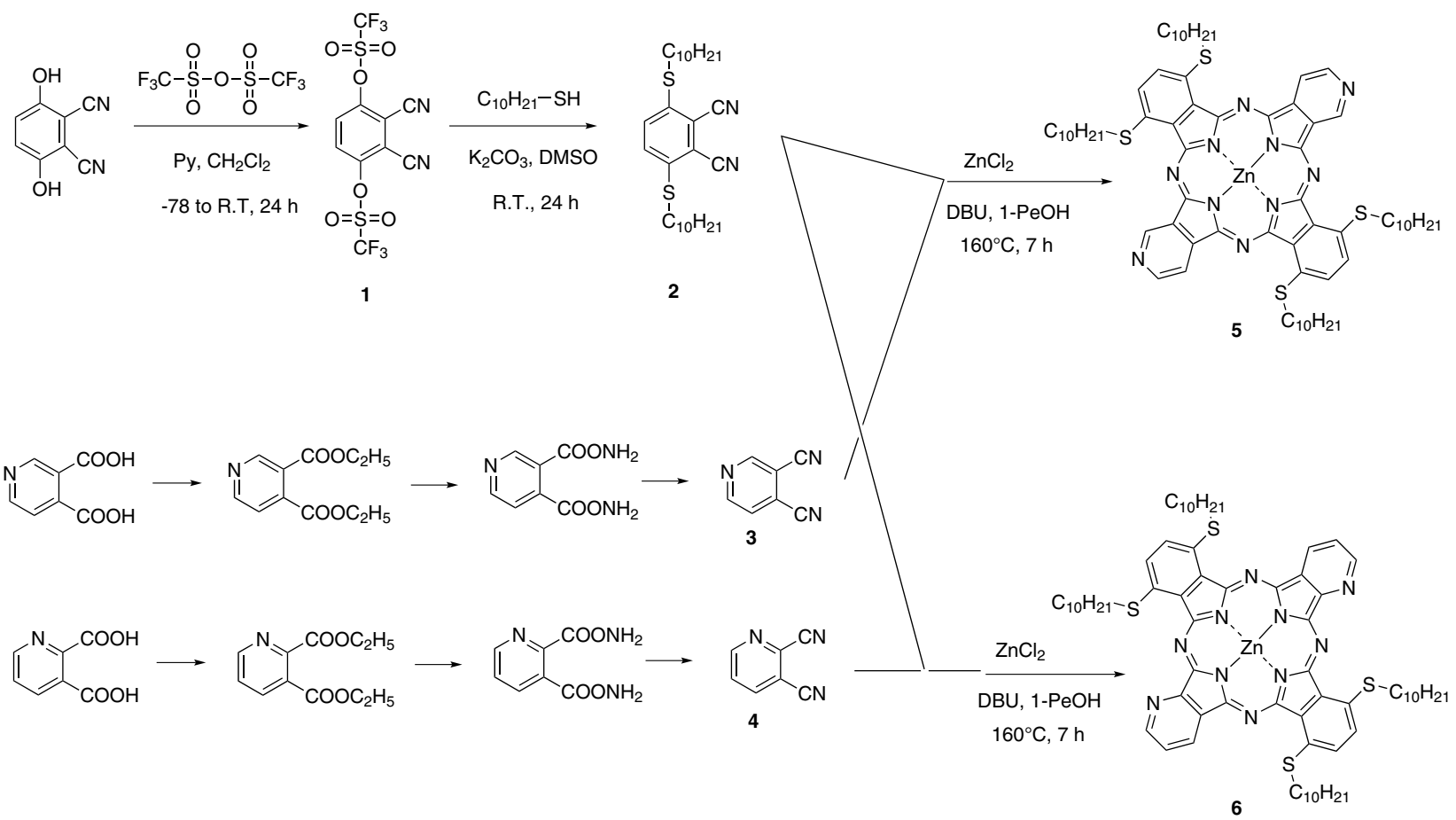

Scheme 1. Synthetic pathway of zinc bis(1,4-didecylthiobenzo)-bis(pyrido)porphyrazines

$\left(v_{\mathrm{C}-\mathrm{C}}\right), 1439\left(v_{\mathrm{C}-\mathrm{C}}\right), 1134\left(v_{\mathrm{S}=\mathrm{O}}\right) .1 \mathrm{H} \mathrm{NMR}(500 \mathrm{MHz}$, DMSO-d $\left.{ }_{6}\right): \delta$, ppm 8.44 (s, 2H). MS (FAB): $\mathrm{m} / \mathrm{z}$ found 396, calcd. 396.26.

Preparation of 3,4-dicyanopyridine (3) and 2,3-dicyanopyridine (4). Compounds 3 and 4 were prepared from pyridine-3,4-dicarboxylic acid (cinchomeronic acid) and pyridine-2,3-dicarboxylic acid (quinolinic acid), respectively by esterification, amidation and dehydration [2].

Product 3 was purified by chromatography over silica gel, $(1.97$ g, $17 \%)$, m.p. $81^{\circ} \mathrm{C}$. Found: C, 65.12\%; H, $2.34 \% ; \mathrm{N}, 32.56 \%$. Calcd. for $\mathrm{C}_{7} \mathrm{H}_{3} \mathrm{~N}_{3}: \mathrm{C}, 65.11 \% ; \mathrm{H}$, $2.34 \% ; \mathrm{N}, 32.55 \%$. IR $(\mathrm{KBr}): \mathrm{cm}^{-1} 3090\left(\mathrm{v}_{\mathrm{C}-\mathrm{H}}\right), 2240$ $\left(v_{\mathrm{C}-\mathrm{N}}\right), 1600\left(\mathrm{v}_{\mathrm{C}-\mathrm{C}}\right), 1550\left(\mathrm{v}_{\mathrm{C}-\mathrm{C}}\right), 1470\left(\mathrm{v}_{\mathrm{C}-\mathrm{C}}\right), 1220\left(\delta_{\mathrm{C}-\mathrm{H}}\right)$, $750\left(\delta_{\mathrm{C}-\mathrm{H}}\right) .{ }^{1} \mathrm{H}$ NMR $\left(400 \mathrm{MHz}, \mathrm{DMSO}-d_{6}\right): \delta$, ppm 9.09 $(\mathrm{s}, 1 \mathrm{H}), 7.75(\mathrm{~s}, 1 \mathrm{H}), 7.26(\mathrm{~s}, 1 \mathrm{H})$. MS (FAB): $\mathrm{m} / \mathrm{z}$ found 129, calcd. 129.13.

Product 4 was purified by chromatography over silica gel, m.p. $85^{\circ}$ C. Found: C, $65.11 \%$; H, 2.33\%; N, 32.56\%. Calcd. for $\mathrm{C}_{7} \mathrm{H}_{3} \mathrm{~N}_{3}: \mathrm{C}, 65.11 \% ; \mathrm{H}, 2.34 \% ; \mathrm{N}, 32.55 \%$. IR $(\mathrm{KBr}): \mathrm{cm}^{-1} 3090\left(\mathrm{v}_{\mathrm{C}-\mathrm{H}}\right), 2240\left(\mathrm{v}_{\mathrm{C}-\mathrm{N}}\right), 1600\left(\mathrm{v}_{\mathrm{C}-\mathrm{C}}\right), 1550$ $\left(v_{\mathrm{C}-\mathrm{C}}\right), 1470\left(\mathrm{v}_{\mathrm{C}-\mathrm{C}}\right), 1220\left(\delta_{\mathrm{C}-\mathrm{H}}\right), 750\left(\delta_{\mathrm{C}-\mathrm{H}}\right) .{ }^{1} \mathrm{H}$ NMR $(400$ MHz, DMSO- $\left.d_{6}\right): \delta$, ppm $8.92(\mathrm{~s}, 1 \mathrm{H}), 8.91(\mathrm{~s}, 1 \mathrm{H}), 8.33$ (s, 1H). MS (FAB): $m / z$ found 129 , calcd. 129.13.

Preparation of zinc bis(1,4-didecylthiobenzo)-bis(pyrido)porphyrazines (5) and (6). Phthalocyanine related compounds, zinc bis(1,4-didecylthiobenzo)-bis(3,4-pyrido)porphyrazine $\mathbf{5}$ and zinc bis(1,4-didecylthiobenzo)bis(2,3-pyrido)porphyrazine $\mathbf{6}$ were prepared by cross cyclotetramerization of intermediate 2 , with 3 or 4 . In the experimental procedure for $\mathbf{5}$, mixtures $\mathbf{2}$ and $\mathbf{3}$ for 1 (0.24 g, $0.6 \mathrm{mmol}): 1$ (0.08 g, $0.6 \mathrm{mmol}) \mathrm{mol}$ ratio, for
6, mixtures 2 and 4 for 1 ( $0.24 \mathrm{~g}, 0.6 \mathrm{mmol})$ : 1 ( $0.08 \mathrm{~g}$, $0.6 \mathrm{mmol}$ ) mol ratio, respectively, were dissolved in pentanol $(1-\mathrm{PeOH})(10 \mathrm{~mL})$ and zinc chloride $\left(\mathrm{ZnCl}_{2}\right)$ $(0.10 \mathrm{~g})$ was added. The mixture was refluxed for $3 \mathrm{~h}$ in the presence of 1,8-diazabicyclo[5.4.0]undec-7-ene (DBU) as a catalyst. After cooling, the reaction mixture was dissolved in toluene $(50 \mathrm{~mL})$ and the solution filtered. The solvent was removed by evaporation. The products were separated and purified by silica gel column chromatography.

Compound 5 was a bluish green solid $(0.51 \mathrm{~g}, 25 \%)$. Found: C, 65.59\%; H, 7.63\%; N, $11.26 \%$. Calcd. for $\mathrm{C}_{68} \mathrm{H}_{94} \mathrm{~N}_{10} \mathrm{~S}_{4} \mathrm{Z}_{\mathrm{n}}: \mathrm{C}, 65.58 \% ; \mathrm{H}, 7.62 \% ; \mathrm{N}, 11.25 \% ; \mathrm{S}$, $10.30 \%$; Zn, 5.25\%. IR (KBr): $\mathrm{cm}^{-1} 3030\left(\mathrm{v}_{\mathrm{C}-\mathrm{H}}\right), 2990$ $\left(v_{\mathrm{C}-\mathrm{H}}\right), 2930\left(v_{\mathrm{C}-\mathrm{H}}\right), 1600\left(\mathrm{v}_{\mathrm{C}-\mathrm{C}}\right), 1510\left(\mathrm{v}_{\mathrm{C}-\mathrm{C}}\right), 1490$ $\left(v_{\mathrm{C}-\mathrm{C}}\right), 690\left(\mathrm{v}_{\mathrm{C}-\mathrm{s}}\right) .{ }^{1} \mathrm{H}$ NMR $\left(500 \mathrm{MHz}, \mathrm{DMSO}-d_{6}\right): \delta$, ppm 9.03-7.35 (m, 10H), 4.52-0.82 (m, 40H). MS (FAB): $\mathrm{m} / \mathrm{z}$ found 1245 , calcd. 1245.41 .

Compound 6 was a bluish green solid $(0.50 \mathrm{~g}, 25 \%)$. Found: C, $65.51 \% ; \mathrm{H}, 7.59 \%$;, $11.22 \%$. Calcd. for $\mathrm{C}_{68} \mathrm{H}_{94} \mathrm{~N}_{10} \mathrm{~S}_{4} \mathrm{Zn}: \mathrm{C}, 65.58 \% ; \mathrm{H}, 7.62 \% ; \mathrm{N}, 11.25 \%$; $\mathrm{S}, 10.30 \%$; Zn, 5.25\%. IR ( KBr): $\mathrm{cm}^{-1} 3030\left(\mathrm{v}_{\mathrm{C}-\mathrm{H}}\right)$, $2990\left(v_{\mathrm{C}-\mathrm{H}}\right), 2930\left(\mathrm{v}_{\mathrm{C}-\mathrm{H}}\right), 1600\left(\mathrm{v}_{\mathrm{C}-\mathrm{C}}\right), 1510\left(\mathrm{v}_{\mathrm{C}-\mathrm{C}}\right), 1490$ $\left(v_{\mathrm{C}-\mathrm{C}}\right), 690\left(\mathrm{v}_{\mathrm{C}-\mathrm{s}}\right) .{ }^{1} \mathrm{H}$ NMR $\left(500 \mathrm{MHz}, \mathrm{DMSO}-d_{6}\right): \delta$, ppm 9.10-7.31 (m, 10H), 4.50-0.75 (m, 40H). MS (FAB): $\mathrm{m} / z$ found 1245 , calcd. 1245.41 .

\section{Quaternization of phthalocyanine related compounds (7) and (8)}

Phthalocyanine-related compounds $\mathbf{5}$ and $\mathbf{6}$ were quaternized with pyridine nitrogen in using dimethyl sulfate 


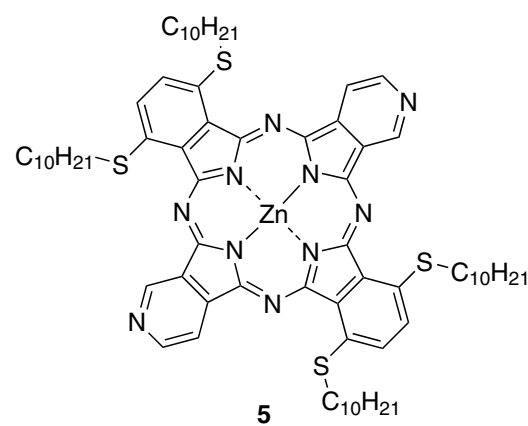
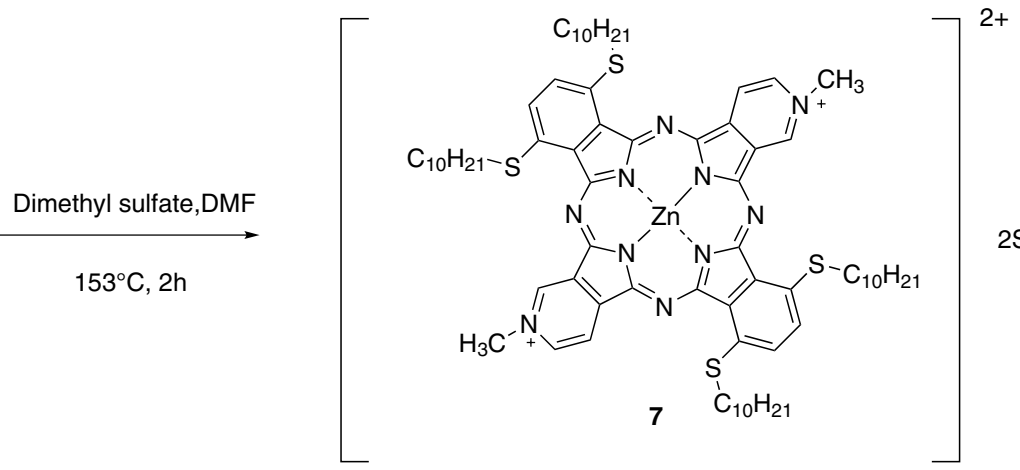

$\mathrm{SO}_{4}{ }^{2-}$

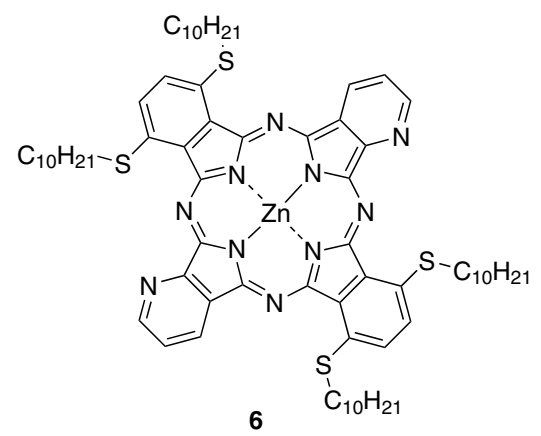
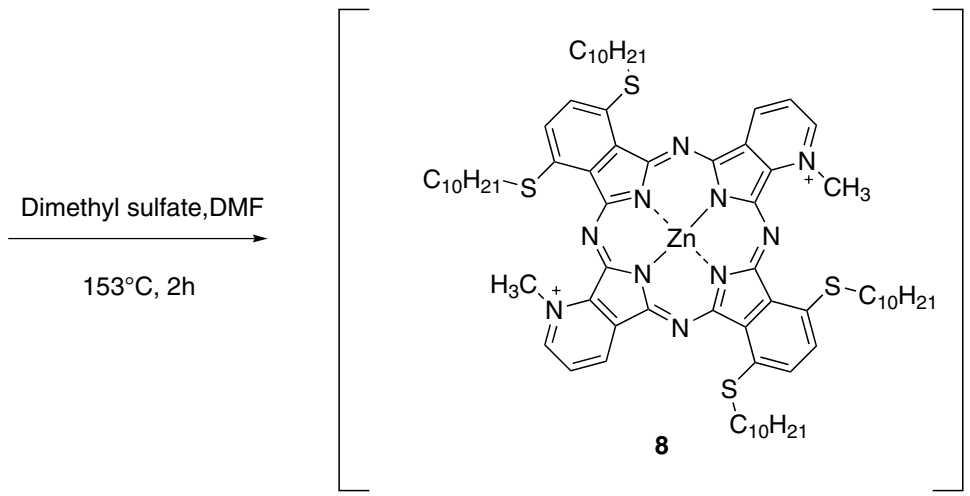

$2+$

$2 \mathrm{SO}_{4}^{2-}$

Scheme 2. Synthesis of quaternized zinc bis(didecylthiobenzo)-bis(pyrido)porphyrazines

to obtain compounds $\mathbf{7}$ and $\mathbf{8}$, respectively. The quaternization route is shown in Scheme 2. A typical quaternization procedure is as follows: compounds 5 or $\mathbf{6}$ $(0.18 \mathrm{~g}, 0.15 \mathrm{mmol})$ were reacted with DMSO (0.2 g, $1 / 55 \mathrm{mmol})$ in DMF $(5 \mathrm{~mL})$ at $153^{\circ} \mathrm{C}$ for $2 \mathrm{~h}$. After reaction, the reaction mixture was dissolved in acetone $(20 \mathrm{~mL})$, cooled to room temperature and the solution filtered. The solvent was removed. The products were purified by TLC (eluent: tetrahydrofuran-toluene, 8:2). Each product was recovered by being scraped from the TLC plate, dissolved in pyridine (py), the solution filtered, and the solvent removed. (a) Compound 7 prepared from 5: dark blue solid (yield 30\%). Found: C, $65.93 \% ; \mathrm{H}, 8.01 \% ; \mathrm{N}, 11.11 \%$. Calcd for $\mathrm{C}_{70} \mathrm{H}_{100} \mathrm{~N}_{10} \mathrm{~S}_{4} \mathrm{Zn}$ : C, $65.91 \%$; H, 7.92\%; N, 10.98\%, S, 10.05\%; Zn, 5.18\%. IR $(\mathrm{KBr}): \mathrm{cm}^{-1} 3030\left(\mathrm{v}_{\mathrm{C}-\mathrm{H}}\right), 2990\left(\mathrm{v}_{\mathrm{C}-\mathrm{H}}\right), 2930\left(\mathrm{v}_{\mathrm{C}-\mathrm{H}}\right), 1600$ $\left(v_{\mathrm{C}-\mathrm{C}}\right), 1510\left(\mathrm{v}_{\mathrm{C}-\mathrm{C}}\right), 1490\left(\mathrm{v}_{\mathrm{C}-\mathrm{C}}\right), 690\left(\mathrm{v}_{\mathrm{C}-\mathrm{s}}\right) .{ }^{1} \mathrm{H}$ NMR $(500$ $\left.\mathrm{MHz}, \mathrm{DMSO}-d_{6}\right): \delta$, ppm 9.03-7.35 (m, 10H), 4.52-0.82 $(\mathrm{m}, 40 \mathrm{H}), 1.05-0.80(\mathrm{~m}, 6 \mathrm{H})$. MS (FAB): $\mathrm{m} / \mathrm{z}$ found 1275, calcd. 1275.49. (b) Compound 8 prepared from $\mathbf{6}$ : dark blue solid (yield 25\%) Found: C, 65.89\%; H, 7.94\%; $\mathrm{N}, 10.86 \%$. Calcd for $\mathrm{C}_{70} \mathrm{H}_{100} \mathrm{~N}_{10} \mathrm{~S}$ Zn: C, $65.91 \% ; \mathrm{H}$, $7.92 \%$; N, $10.98 \%, S, 10.05 \%$; Zn, 5.18\%. IR (KBr): $\mathrm{cm}^{-1} 3030\left(\mathrm{v}_{\mathrm{C}-\mathrm{H}}\right), 2990\left(\mathrm{v}_{\mathrm{C}-\mathrm{H}}\right), 2930\left(\mathrm{v}_{\mathrm{C}-\mathrm{H}}\right), 1600\left(\mathrm{v}_{\mathrm{C}-\mathrm{C}}\right)$, $1510\left(v_{\mathrm{C}-\mathrm{C}}\right), 1490\left(\mathrm{v}_{\mathrm{C}-\mathrm{C}}\right), 690\left(\mathrm{v}_{\mathrm{C}-\mathrm{s}}\right) .{ }^{1} \mathrm{H}$ NMR $(500 \mathrm{MHz}$, DMSO- $\left.d_{6}\right): \delta$, ppm 9.10-7.31 (m, 10H), 4.50-0.75 (m, $40 \mathrm{H}) .1 .08-0.75(\mathrm{~m}, 6 \mathrm{H})$. MS (FAB): $\mathrm{m} / \mathrm{z}$ found 1276 , calcd. 1275.49.

\section{RESULTS AND DISCUSSION}

\section{Synthesis}

Synthetic routes of the target compounds $\mathbf{5}$ and $\mathbf{6}$, and their intermediates 1-4 are summarized in Scheme 1.

The target compound zinc bis(didecylthiobenzo)bis(pyrido)porphyrazines were synthesized by cross cyclotetramerization between their intermediates 3,6bis(decylthio)phthalonitrile (2) and 3,4-dicyanopyridine (3) or 2,3-dicyanopyridine (4). Intermediate $\mathbf{2}$ was synthesized from phthalonitrile-3,6-ditrifluoromethanesulfate (1) and decanethiol. Intermediate $\mathbf{1}$ was synthesized from 2,3-dicyanohydroquinone and trifluoromethanesulfonic anhydride for $24 \mathrm{~h}$ in accordance with a description from the literature [3]. The other intermediates $\mathbf{3}$ and $\mathbf{4}$ were synthesized from pyridine3,4-dicarboxylic acid (cinchomeronic acid) and pyridine2,3-dicarboxylic acid (quinolinic acid), respectively, via their diethyl ether and diamide. The intermediates $\mathbf{1}$ to $\mathbf{4}$ were analyzed using IR, ${ }^{1} \mathrm{H}$ NMR and MS spectra and elemental analysis. Their analytical data showed good agreement with the proposed structure.

The target compounds zinc bis(1,4-didecylthiobenzo)bis(3,4-pyrido)porphyrazine (5) and zinc bis(1,4didecylthiobenzo)-bis(2,3-pyrido)porphyrazine (6) were synthesized respectively from $\mathbf{3}$ and $\mathbf{4}$ with $\mathbf{2}$ and $\mathrm{ZnCl}_{2}$ in the presence of $\mathrm{DBU}$ as a catalyst by refluxing in 
1-PeOH. The products were isolated using column chromatography on silica gel with $\mathrm{CHCl}_{3}$ and py as eluent. The target compounds $\mathbf{5}$ and $\mathbf{6}$ were analyzed using elemental analysis, IR, ${ }^{1} \mathrm{H}$ NMR and MS spectra. The analytical data showed good agreement with the proposed structures.

In general, phthalocyanines and their related compounds can be prepared from cyclotetramerization of the appropriate phthalic acid derivatives such as the anhydride, amide or dinitrile. Undoubtedly, the obtained phthalocyanines and their related compounds were composed of only one constituent, while on the other hand, it is thought that target compounds zinc bis(didecylthiobenzo)-bis(pyrido)porphyrazines $\mathbf{5}$ and 6, synthesized from mixed raw materials by cross cyclotetramerization, were prepared as a mixture of products which have different number of pyridine rings in the molecule. The authors previously reported that alkylbenzopyridoporphyrazine synthesized from mixed raw materials has desired molecular structure for its main constituents [11].

As reported earlier, it was expected that the zinc bis(didecylthiobenzo)-bis(pyrido)porphyrazines $\mathbf{5}$ and 6 prepared by cross cyclotetramerization of mixed materials would have the proposed molecular structure in accordance with the stoichiometric coefficient. As the synthesized $\mathbf{5}$ and $\mathbf{6}$ were purified by TLC (eluent: toluene), each product had only one constituent. These results mean that the $\mathbf{5}$ and $\mathbf{6}$ have a proposed structure in accordance with the stoichiometric ratio. Of course, each compound is a mixture of five regioisomers which possess two pyridine rings and two non-peripheral substituted benzenoid rings at different locations in the molecules as previously reported [11]. In Scheme 1, typical molecular structures of $\mathbf{5}$ and $\mathbf{6}$ are described.

\section{Photochemical property}

The fluorescence spectrum of a compound is generally known to be the mirror image of its UV-Vis spectrum. The difference between absorption maxima of UV-Vis or excitation spectra and peak of fluorescence spectra is known as the Stokes shift.

UV-Vis, excitation and fluorescence spectral data of compounds 5, $\mathbf{6}$ and reference compounds are shown in Table 1 .
The strongest absorption of phthalocyanines is detected in the visible region between the 650 and $690 \mathrm{~nm}, \mathrm{Q}$ band, and in UV between 320 and $370 \mathrm{~nm}$, called the Soret band. A typical value for the extinction coefficient $(\varepsilon)$ of the Q band is around $10^{5} \mathrm{~cm}^{2} \mathrm{~mol}^{-1}$. The $\mathrm{Q}$ band is attributed to the allowed HOMO-LUMO, $\pi-\pi^{*}$ transition of the phthalocyanine ring. The $\log \varepsilon$ for the $\mathrm{Q}$ band of $\mathbf{5}$ and $\mathbf{6}$ is estimated to be around 5 .

In our previous study, the $\mathrm{Q}$ bands of unsubstituted zinc phthalocyanine and zinc 1,4,8,11,15,18,22,25octakis(didecylocytobenzo)phthalocyanine showed at 650 (see Table 1) and $792 \mathrm{~nm}$ [3]. With regard to UV-Vis spectra, the Q band of compound 5 shows 676 $\mathrm{nm}$, which is shifted by $26 \mathrm{~nm}$ to longer wavelengths in comparison to unsubstituted zinc phthalocyanine, while in the case of compound $\mathbf{6}$, the Q band shows $646 \mathrm{~nm}$, then no bathochromic effect is observed. The $\mathrm{Q}$ band shift of compound $\mathbf{5}$ depends upon the change in the electron distribution in the phthalocyanine ring caused by thioalkyl groups and nitrogen atoms in pyridine rings. Whereas in the case of compound $\mathbf{6}$, it is thought that the position of nitrogen atoms in pyridine rings counteracts the bathochromic effect of thiodidecyl groups.

The shapes and maximum wavelength $\left(\lambda_{\max }\right)$ of UV-Vis spectra correspond to almost the same excitation maxima $\left(\lambda_{\mathrm{ex}}\right)$. Then fluorescence maxima $\left(F_{\max }\right)$ of $\mathbf{5}$ and 6 appeared 741 and $702 \mathrm{~nm}$, respectively. The difference between $\lambda_{\max }$ or $\lambda_{\text {ex }}$ and $F_{\text {max }}$ showed to be approximately $60 \mathrm{~nm}$ in the case of $\mathbf{5}$ and $\mathbf{6}$. Fluorescence is reflected as aromatic double-bonded with a high degree of resonance stability. The same as $F_{\max }$ signifies dependence on the $\pi$ electron environment. In the case of phthalocyanines, the Stokes shift overlaps with the wavelength at which fluorescence occurs, since the structure of the molecule changes little between the grand and excited electronic states due to the rigid structure [13]. In the case of target compounds $\mathbf{5}$ and $\mathbf{6}$, the molecular transformation depends upon their structures between electron transitions because their constitutions exhibit flexibility as a result of thioalkyl substituents in its molecule.

\section{Photophysical property}

Fluorescence peaks and transient decays were observed upon pulsed excitation $(355 \mathrm{~nm})$ in $1.5 \times 10^{-5} \mathrm{M}$ $\mathrm{CHCl}_{3}$ solution. The transient absorption was reasonably

Table 1. UV-Vis, excitation and fluorescence spectral data of target compounds 5 and $\mathbf{6}$

\begin{tabular}{|c|c|c|c|c|c|}
\hline \multirow[t]{2}{*}{ Compound } & \multicolumn{2}{|c|}{ Q Band } & \multirow{2}{*}{$\frac{\text { Excitation }}{\lambda_{\mathrm{ex}} / \mathrm{nm}}$} & \multirow{2}{*}{$\frac{\text { Fluorescence }}{F_{\max } / \mathrm{nm}}$} & \multirow{2}{*}{$\frac{\text { Stokes shift }}{\Delta_{\text {Stokes }} / \mathrm{nm}}$} \\
\hline & 741 & $\log \varepsilon$ & & & \\
\hline Zinc phthalocyanine & 702 & 5.154 & 650 & 669 & 19 \\
\hline 5 & 676 & 5.186 & 676 & 741 & 65 \\
\hline 6 & 646 & 5.551 & 646 & 702 & 56 \\
\hline $\begin{array}{l}\text { 1,4,8,11,15,18,23,35-Octakis(didecylthio- } \\
\text { benzo)phthalocyanine }\end{array}$ & 783 & 4.2 & & & Ref. 3 \\
\hline
\end{tabular}


Table 2. Photophysical parameters of target compounds 5 and 6

\begin{tabular}{lcc}
\hline Compound & Triplet lifetime $/ \mu \mathrm{s}$ & $\Phi_{\Delta}$ \\
\hline Zinc phthalocyanine & 0.4 & 0.64 \\
$\mathbf{5}$ & 1.2 & 0.43 \\
$\mathbf{6}$ & 1.2 & 0.43 \\
\hline
\end{tabular}

assigned to the triplet state. The strongest fluorescence was quenched by oxygen for laser flash excitation of $560 \mathrm{~nm}$. A similar decay curve was obtained for compound 6. Transient absorptions were reasonably assigned to the triplet state. The strongest fluorescence was quenched by oxygen for the laser-flash excitation of $560 \mathrm{~nm}$.

The photoexcited triplet state lifetimes of $\mathbf{5}$ and $\mathbf{6}$ are shown in Table 2. The photoexcited triplet state lifetime of $\mathbf{5}$ and $\mathbf{6}$ were estimation to be around $1.2 \mu \mathrm{s}$. Photooxidation progresses via singlet oxygen $\left({ }^{1} \mathrm{O}_{2}\right)$ in the presence of phthalocyanines and their related compounds as a photosensitizer [2]. Phthalocyanines and their related compounds include compounds 5 and $\mathbf{6}$ in the excited triplet state react with ground triplet state oxygen $\left({ }^{3} \mathrm{O}_{2}\right)$.

Non-transition metal phthalocyanines, especially aluminium and zinc, are excellent photosensitizers for the type II mechanism because they exhibit high triplet lifetimes and give high quantum yields for ${ }^{1} \mathrm{O}_{2}$ formation $[2,3,9,13]$. The ${ }^{1} \mathrm{O}_{2}$ reacts with a substrate to produce oxide in accordance with the type II mechanism [2].

The photochemistry of target compounds $\mathbf{5}$ and $\mathbf{6}$ results in the same process of the above-mentioned type II mechanism shown in Equations 1-3.

\section{Compound 5 and $\mathbf{6} \stackrel{h v}{\longrightarrow}$ Singlet state of 5 and $\mathbf{6}$ \\ $\stackrel{\text { Intersystem crossing }}{\longrightarrow}$ Triplet state of $\mathbf{5}$ and $\mathbf{6}$}

Triplet state of 5 and $6+{ }^{3} \mathrm{O}_{2} \rightarrow$ Compound 5 and $6+{ }^{1} \mathrm{O}_{2}$

$$
{ }^{1} \mathrm{O}_{2}+\text { substrate } \rightarrow \text { substrate oxide }
$$

The $\Phi_{\Delta}$ were estimated using Equation 4 , in which $\Phi_{\Delta}$ indicates the potential of the photosensitizer in applications where singlet oxygen is required in a type II mechanism. The values of $\Phi_{\Delta}$ were determined in air with zinc phthalocyanine as the standard material, and DPBF was used as chemical quencher for singlet oxygen. An efficacy of singlet oxygen quenching is monitored by decrease of DPBF peak intensity at $416 \mathrm{~nm}$ on UV-Vis spectra.

$$
\Phi_{\Delta}=\Phi_{\Delta}^{\mathrm{Std}} \frac{R I_{\mathrm{abs}}^{\mathrm{Std}}}{R^{\text {Std }} I_{\mathrm{abs}}}
$$

where $\Phi_{\Delta}^{\text {Std }}$ is the singlet oxygen quantam yields for zinc phthalocyanine as a standard $\Phi_{\Delta}^{\text {Std }}=0.67$ in DMF, $R$ and $R^{\text {Std }}$ are the DPBF photobleaching rate in the presence

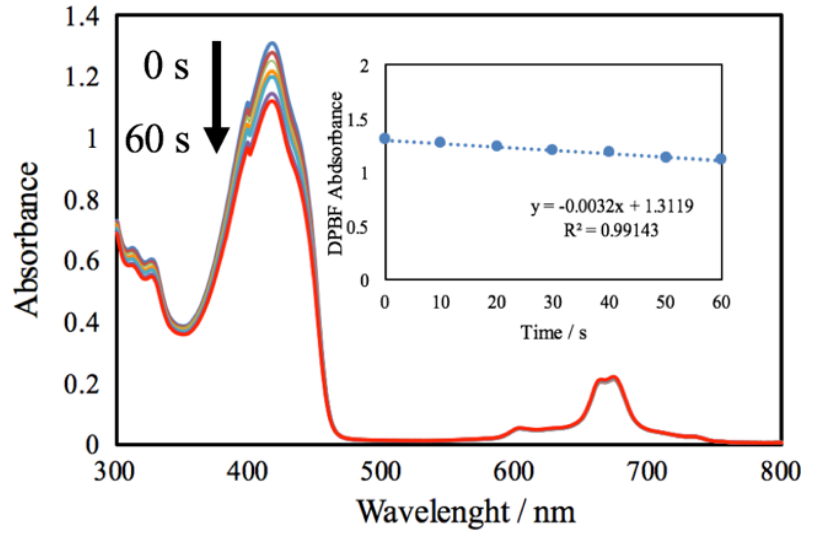

Fig. 1. A typical spectrum for the determination of singlet oxygen quantum yield of compound $\mathbf{5}$ in DMF using DPBF as a singlet oxygen quencher

of compounds (5 and 6) and zinc phthalocyanine was the standard, respectively. Symbols $I_{\mathrm{abs}}$ and $I_{\mathrm{abs}}^{\text {Std }}$ are compounds (5 and 6) and zinc phthalocyanine.

UV-Vis spectra for determination of $\Phi_{\Delta}$ compound $\mathbf{5}$ using DPBF shown in Fig. 1. Absorption bands appeared at 416 and $676 \mathrm{~nm}$ for DPBF and the $\mathrm{Q}$ band of compound 5, respectively. The intensity of the DPBF peaks at $416 \mathrm{~nm}$ decreased with increasing elapsed time, while no change was observed for the Q band of 5 at $676 \mathrm{~nm}$ during $\Phi_{\Delta}$ measurements. The DPBF absorbance at $416 \mathrm{~nm}$ was decreased in proportion to the elapsed time. The relationship is shown in the inset in Fig. 1. The $\Phi_{\Delta}$ of compound $\mathbf{5}$ was estimated to be 0.43 , which had a lower value than the standard zinc phthalocyanine $(0.64$, Table 2). The $\Phi_{\Delta}$ value is considered to be sufficient to utilize as a photosensitizer for PDT [5, 8]. A similar observation was obtained for compound $\mathbf{6}$.

\section{Quaternization of compounds 5 and 6}

Compounds 5 and $\mathbf{6}$ were reacted with a quaternizing agent such as dimethyl sulfate in DMF as solvent at $153^{\circ} \mathrm{C}$ for $2 \mathrm{~h}$ (Scheme 2). Yields of quaternized zinc bis(1,4-didecylthiobenzo)-bis(3,4-pyrido)porphyrazines (7) and quaternized zinc bis(1,4-didecylthiobenzo)bis(2,3-pyrido)porphyrazines (8) were 30 and 25\%, respectively. The quaternized compounds $\mathbf{7}$ and $\mathbf{8}$ were analyzed using IR and ${ }^{1} \mathrm{H}$ NMR spectra. Their analytical data showed good agreement with the proposed structure.

\section{Acknowledgements}

We thank our students, Mr. Yuma Sakaguchi and Miss Yumiko Igarashi for their experimental assistance.

\section{REFERENCES}

1. Sakamoto K, Yoshino S, Takemoto M, Sugaya K, Kubo H, Komoriya T, Kamei S and Furukawa S. J. Porphyrins Phthalocyanines 2015; 19: 688-694. 
2. Sakamoto K, Yoshino S, Takemoto M and Furuya N. J. Porphyrins Phthalocyanines 2013; 17: 605-627.

3. Sakamoto K, Ohno-Okumura E, Kato T and Soga H. J. Porphyrins Phthalocyanines 2010; 14: 47-54.

4. Campidell S, Ballesteros B, Filoramo A, Diaz D, de la Torre G, Torres T, Rahman GMA, Aminur EC, Kissing D, Werner F, Sgobba V, Guldi DM, Cioffi C, Prato M and Bourgoin J-P. J. Am. Chem. Soc. 2008; 130: 11503-11509.

5. Drumuş M, Yaman H, Göl C, Ahsen V and Nykong T. Dyes Pigm. 2011; 91: 153-163.

6. Ichikawa M, Kobayashi K, Koyama T and Taniguchi Y. Thin Solid Films 2007; 515: 3932-3935.

7. Sharma U, Verma PK, Kumar N, Kumar V, Bala M and Singh B. Chem.-Eur. J. 2011; 17: 5903-5907.

8. Khoza P, Antunes E and Nyokong T. Polyhedron 2013; 61: 119-125.

9. Sakamoto K, Kato T, Ohno-Okumura E, Watanabe $\mathrm{M}$ and Cook MJ. Dyes Pigm. 2005; 64: 63-71.
10. Jori G. Photochem. Photobiol. 1990; 52: 439-443.

11. Sakamoto K, Kato T and Cook MJ. J. Porphyrins Phthalocyanines 2001; 5: 742-750.

12. Shigeno A, Matsuno T, Hirota $S$ and Shinokubo H. Chem. Lett. 2015; 44: 1703-1705.

13. Sakamoto K, Ohno-Okumura E, Kato T, Watanabe M and Cook MJ. Dyes Pigm. 2008; 78: 213-218.

14. Sakamoto K, Yoshino S, Takemoto M, Sugaya K, Kubo H, Komoriya T, Kamei S and Furukawa S. Am. J. Anal. Chem. 2014; 5: 1037-1045.

15. Nymykin VN, Dudkin SV, Dumoulin F, Hirel C, Gurek AG, Ahsen V. ARKIVOC 2014; 142-204.

16. Bottari G, de la Torre G and Torres T. Accounts of Chem. Res. 2015; 48: 900-910.

17. Ragolissi M-E and Torres T. Chem. Commun. 2015; 51: 3957-3972. 